\title{
Editorial:
}

\section{Depression in Elderly People: Ideas for Research and Services}

Until recently, dementia was virtually the only legitimate area of research in geriatric psychiatry and clinical geropsychology. Glancing at the program of any scientific gathering or the tables of contents of learned periodicals in gerontology and geriatrics, we find that topics related to dementia still take up most of the space. Over the last ten years or so, however, a lot more attention has been paid to depression among older adults. Two articles in this issue (Bachelor; Bizzini \& Myers-Arrazola) reflect the contribution of psychology in this area. Publishing them both at once provides an opportunity to discuss theoretical models and psychotherapeutic interventions in order to identify various avenues for developing research and services.

Epidemiological considerations and the outlook for the near future justify focusing on geriatric depression. Contemporary research in epidemiology has found that age is not an independent risk factor for major depression, the symptomatology of which fits the criteria of psychiatric diagnostics. Contrary to what is commonly believed, the point prevalence of this diagnosis among the elderly is not higher than for the reference population of young and middle-aged adults, and may even be lower (see, among others: Cappeliez, 1993; Blazer, 1994). Although this overall finding may appear reassuring, it may turn out to apply only to the current generation of over-65.

To begin with, multiplying this rate by the demographic weight of the post-war generation (baby-boomers) shows how major a concern geriatric depression will be in the public health field in the next few decades. This demographic phenomenon could be amplified by a period effect. Actually, an increased frequency of major depressions in all cohorts was observed in the mid-1960s with another upward trend in the 1970s (Warshaw, Klerman, \& Pavori, 1991). Depression also appears to be becoming more common among young people, with early onset in adolescence (Burke, Burke, Regier, \& Rae, 1990; Klerman \& Weissman, 1989). Because depression is typically characterized by recurrence (5-6 episodes during a person's lifetime), we can expect to see an increase in the number of elderly people suffering from depression. Other factors also come into play. These global statistics partially mask the higher incidence of depression among sub-groups of the elderly, especially those with physical ailments and those taking care of a cognitively deficient spouse (caregivers), two groups that will be growing as elderly people live longer. The problems of depression among those providing continuous care for a family member with Alzheimer's disease are currently attracting a great deal of attention from researchers and mental health professionals (Mohide \& Streiner, 1993). Most studies report clinical depression as frequent among this group of elderly people (Redinbaugh, 
MacCallum, \& Kiecolt-Glaser, 1995). Moreover, without necessarily calling into question present-day diagnostic methods, a number of specialists are wondering about their ability to adequately capture the scope of the problem of depression among the aged. Thus, Blazer (1994) recently proposed using minor depression as a diagnostic category, meaning depression that is less severe than major depression but debilitating nonetheless. Some data suggest a high incidence of this level of depression among elderly people (see Cappeliez, 1993; Newmann, 1989). Among those with physical ailments, these cases of depression are associated with increased functional disability, longer hospital stays and greater use of health services (Mossey, 1993). Finally, we should not forget the enormous financial burden that problems of depression place on the resources of our society (Rice \& Miller, 1995).

Until now, the theoretical models that can help us understand geriatric depression and formulate our psychotherapeutic interventions have mainly been derived from conceptualizations of depression among young or middleaged adults. That is why the pioneering work of Bachelor presented in this issue is so relevant. She begins by describing the distinctive features of depression in the light of three approaches commonly used today (the cognitive and psychodynamic approaches as well as the revised version of the model of learned helplessness). Each of these three approaches offers a grid for identifying the depressive symptoms relevant to the model and emphasizes some personality characteristics which may render some individuals vulnerable to depression. The author concludes that depression in an elderly person also involves the psychological processes proposed by the theories examined. This shows the relevance of these theoretical approaches for the understanding of depression among the elderly and places the study of geriatric depression firmly in a perspective of continuity of adult development. Indirectly, this conclusion encourages the use of psychotherapies deriving from these theoretical approaches.

In one form or another, the theories that Bachelor examines are built around the concept that the main problems encountered by a depressed person are in the field of vocational achievements (work) and interpersonal relations, especially marital (love). We know that in old age, the precipitating factors of depression are more often related to physical illness (see Cappeliez, 1993). This aspect of depression in old age has not yet been satisfactorily integrated with the vulnerability characteristics in the models examined by Bachelor. Beyond the specific objective of this article, the experimental endeavour begun here could be extended to include an approach such as reminiscence, which integrates the dimension of life-meaning in psychotherapy with depressive elderly people (Watt \& Cappeliez, 1995). This aspect seems fundamental in clinical work with the elderly, yet it has hardly been developed in the contemporary cognitive and psychodynamic approaches to depression. It would also be judicious to take into consideration the contextual factors of depression in the elderly (e.g., somatic, social and economic stressors; social representations and comparisons; interpersonal relationships) rather than just intra-individual factors. Cognitive ap- 
proaches to depression have in fact been severely criticized for not giving enough importance to social factors in their understanding and treatment of depression (Cappeliez \& Flynn, 1993; Coyne \& Whiffen, 1995; Champion \& Power, 1995; Lyddon, 1995).

In addition to the emphasis that psychiatry places on the biological roots of geriatric depression, the feeling among clinicians that elderly people are not good candidates for psychotherapy has delayed the development of research and services. The pervasiveness of this negative bias regarding the benefits that elderly people can derive from psychotherapy has been recently documented. This attitude is shared by the general public (Zivian, Larsen, Gekoski, Knox, \& Hatchette, 1994) and by clinicians themselves (Zivian, Larsen, Knox, Gekoski, \& Hatchette, 1992). However, research into the effectiveness of psychotherapy is showing promising results. Comparisons between psychotherapeutic approaches (behavioural, psychodynamic, cognitive, reminiscence) show that all are equally effective (Niederehe, 1994; Scogin \& McElreath, 1994). These studies clearly indicate the benefit that elderly people can derive from such treatment.

The article by Bizzini and Myers-Arrazola stands on the brink of a second stage of research seeking to define the therapeutic principles and processes at work in cognitive therapy of depression. It describes a case study, giving a qualitative observation and narrative description of the progress of the case, an approach that is the basis of any psychotherapeutic enterprise. This contribution is highly topical, with the renewed interest in single case research protocols in clinical psychology (Long \& Hollin, 1995). Combining as it does both qualitative and quantitative analysis, this study is a good illustration of the contribution made by the European tradition to clinical psychology in general, and treatment of the elderly in particular. Readers who are less familiar with the approach will find that its narrative format enables them to grasp the complexity of cognitive therapy.

Most of the initial research into psychotherapy for depressed elderly people has typically been conducted with subjects without comorbidity (dementia, anxiety, disorders alcohol abuse, personality disorders), who are younger, in good physical and cognitive condition, educated and motivated. Inspired by the works presented here, we must now develop interventions suited to the needs of depressive elderly people who do not have all these favourable characteristics. Studies conducted in the natural clinical context are urgently required to examine the scope and clinical significance of the promising results obtained under laboratory-like conditions. We must also focus on individuals who respond poorly to psychotherapeutic interventions, in order to improve our services. More generally, given the confirmed potential of psychotherapy, those who intervene must be trained in these approaches and the public must be made aware of its availability and its potential of success. Given their key position in health care services for the elderly, family physicians and professionals working in community health centres are called upon to familiarize themselves with the effective treatments available and, depending on their professional skills, seek training in 
these interventions or refer their patients to the appropriate services.

In conclusion, I would like to take this opportunity to call for increased research efforts in the field of geriatric depression. At present, Alzheimer's disease is clearly receiving the lion's share of the resources for research in gerontology and geriatrics. Various authors have criticized the negative impact of this "Alzheimerization" (Adelman, 1995) or, more generally, "biomedicalization" (Estes \& Binney, 1989) of aging on the development of knowledge in other fundamental areas such as biology and the social sciences. Without wishing in any way to diminish the importance of research into Alzheimer's disease, the publication of these articles on depression provides an opportunity to plead the case for increased funding for research into other areas of mental health, among them depression.

\section{References}

Adelman, R.C. (1995). The Alzheimization of aging. The Gerontologist, 35, 526-532. Blazer, D.G. (1994). Epidemiology of late-life depression. In L.S. Schneider, C.F. Reynolds, B.D. Lebowitz, \& A.J. Friedhoff (Eds.), Diagnosis and treatment of depression in late life: Results of the NIH Consensus Development Conference (pp. 9-19). Washington, DC: American Psychiatric Press.

Burke, K.C., Burke, J.D., Regier, D.A., \& Rae, D.S. (1990). Age at onset of selected mental disorders in five community populations. Archives of General Psychiatry, 47, 511-518.

Cappeliez, P. (1993). Depression in elderly persons: Prevalence, predictors, and psychological intervention. In P. Cappeliez \& R.J. Flynn (Eds.), Depression and the social environment: Research and intervention with neglected populations (pp. 332-368). Montreal: McGill-Queen's University Press.

Cappeliez, P., \& Flynn, R.J. (1993). An integrative cognitive-environmental view of depression. In P. Cappeliez \& R.J. Flynn (Eds.), Depression and the social environment: Research and intervention with neglected populations (pp. 1-11). Montreal: McGill-Queen's University Press.

Champion, L.A., \& Power, M.J. (1995). Social and cognitive approaches to depression: Towards a new synthesis. British Journal of Clinical Psychology, 34, 485-503.

Coyne, J.C., \& Whiffen, V.E. (1995). Issues in personality as diathesis for depression: The case of sociotropy-dependency and autonomy-self-criticism. Psychological Bulletin, 118, 358-378.

Estes, C.L., \& Binney, F.A. (1989). The biomedicalization of aging: Dangers and dilemnas. The Gerontologist, 29, 587-596.

Klerman, G.L., \& Weissman, M.M. (1989). Increasing rates of depression. Journal of the American Medical Association, 261, 2229-2235.

Long, C.G., \& Hollin, C.R. (1995). Single case design: A critique of methodology and analysis of recent trends. Clinical Psychology and Psychotherapy, 2, 177-191.

Lyddon, W.J. (1995). Cognitive therapy and theories of knowing: A social constructionist view. Journal of Counseling \& Development, 73, 579-585.

Mohide, E.A., \& Streiner, D.L. (1993). Depression in caregivers of impaired elderly family members. In P. Cappeliez \& R.J. Flynn (Eds.), Depression and the social environment: Research and intervention with neglected populations (pp. 289-331). Montreal: McGill-Queen's University Press. 
Mossey, J. (1993, novembre). Subsyndromal depression in the elderly: Epidemiological, clinical and treatment aspects. Symposium at the annual meetings of the Gerontological Society of America, New Orleans, LA.

Newmann, J.P. (1989). Aging and depression. Psychology and Aging, 4, 150-165.

Niederehe, G.T. (1994). Psychosocial therapies with depressed older adults. In L.S. Schneider, C.F. Reynolds, B.D. Lebowitz, \& A.J. Friedhoff (Eds.), Diagnosis and treatment of depression in late life: Results of the NIH Consensus Development Conference (pp. 293-315). Washington, DC: American Psychiatric Press.

Redinbaugh, E.M., MacCallum, R.C., \& Kiecolt-Glaser, J.K. (1995). Recurrent syndromal depression in caregivers. Psychology and Aging, 10, 358-368.

Rice, D.P., \& Miller, L.S. (1995). The economic burden of affective disorders. British Journal of Psychiatry, 166 (suppl. 27), 34-42.

Scogin, F., \& McElreath, L. (1994). Efficacy of psychosocial treatments for geriatric depression: A quanititative review, Journal of Consulting and Clinical Psychology, 62, 69-74.

Warshaw, M.G., Klerman, G.L., \& Pavori, P.W. (1991). The use of conditional probablities to examine age-period-cohort data: Further evidence for a period effect in major depressive disorder. Journal of Affective Disorders, 23, 119-129.

Watt, L.M., \& Cappeliez, P. (1995). Reminiscence interventions for the treatment of depression in older adults. In B.K. Haight \& J.D. Webster (Eds.) The art and science of reminiscing: Theory, research, methods, and applications (pp. 221232). Washington, DC: Taylor \& Francis.

Zivian, M.T., Larsen, W., Gekoski, W., Knox, V.J., \& Hatchette, V.(1994). Psychotherapy for the elderly: Public opinion. Psychotherapy, 31, 492-502.

Zivian, M.T., Larsen, W., Knox, V.J., Gekoski, W.L., \& Hatchette, V. (1992). Psychotherapy for the elderly: Psychotherapists' preferences. Psychotherapy, 29, 668-674.

Philippe Cappeliez 